\title{
Prevalence and Factors Associated with Tobacco Consumption Among Students of a Selected Private University in Bangladesh
}

\author{
(D) Salman Mohamed Farah, ${ }^{1}$ (i) ABM Alauddin Chowdhury, ${ }^{1}$ (i) Lucila Nascimento, ${ }^{2}$ \\ D Dionéia Monte-Serrat, ${ }^{3}$ (D) Rosanna De La Rosa-Eduardo, ${ }^{4}$ (1) Russell Kabir, \\ D. Kamrul Hossain ${ }^{6}$
}

\author{
'Department of Public Health, Daffodil International University, Dhaka, Bangladesh \\ ${ }^{2}$ Ribeirão Preto College of Nursing, Ribeirão Preto, São Paulo, Brazil \\ ${ }^{3}$ Universidade de Ribeirao Preto, Sao Paulo State, Brazil \\ ${ }^{4}$ Área de Enfermería, Departamento de Ciencias de la Salud, Universidad Pública de Navarra, Spain \\ ${ }^{5}$ School of Allied Health, Anglia Ruskin University, Essex, UK \\ ${ }^{6}$ Department of General Educational Development, Daffodil International University, Dhaka, Bangladesh
}

\section{ABSTRACT}

Please cite this article as: Farah SM, Chowdhury ABMA, Nascimento L, Monte-Serrat D, De La Rosa-Eduardo R, Kabir R, et al. Prevalence and Factors Associated with Tobacco Consumptionamong Students of a Selected Private University in Bangladesh. Anatol J Family Med 2020;3(1):22-30.

Address for correspondence: Dr. Russell Kabir. School of Allied Health, Anglia Ruskin University, Essex, UK

Phone: +447551333103

E-mail: russell.kabir@anglia.ac.uk

Received Date: 24.04.2019

Accepted Date: 07.06.2019

Published online: 01.04.2020

(C) Copyright 2020 by Anatolian Journal of Family Medicine -

Available online at www.anatoljfm.org

OPEN ACCESS

Objectives: Tobacco consumption has a significant association with several health problems. Among the eight leading causes of morbidity and mortality, tobacco consumption is the major risk factor for six causes. This study aimed to find out the prevalence and the factors associated with tobacco consumption among the students at a private university.

Methods: This cross-sectional study was conducted at Daffodil International University from January to May 2017, and data were collected using a structured questionnaire.

Results: A total of 384 students participated in this study. The findings showed that 184 (48.4\%) of the students of a private university were smoking any form of tobacco. Age, place of residence, knowledge of the consequences of tobacco consumption, health problems that the respondents were suffering, an affair of love, the frequency of library had a significant association with tobacco consumption.

Conclusion: Identifying associated risk factors is important to develop a prevention program and mitigate the epidemic situation of tobacco consumption among the students.

Keywords: Bangladesh, risk factors, students, tobacco consumption, universities

\section{INTRODUCTION}

The tobacco epidemic is one of the biggest threats to public health. Due to this threat, more than 5 million are dying for direct tobacco consumption and near to 1 million deaths of non-smokers being exposed to second-hand smoke. ${ }^{[1]}$ It is established in public health that tobacco consumption is a proven risk factor. Tobacco consumption has a substantial contribution to raising the epidemic of non-communicable diseases. ${ }^{[2]}$ Nearly four out of 
five smokers lived in low- and middle-income countries where the expense on tobacco, tobacco-related illness and death are the heaviest burden. ${ }^{[3]}$ The tobacco consumption in the form of smoke or smokeless is higher in the South-East Asian region. A study revealed that among Bangladeshi, the rate of death due to tobacco is 28 persons per hour, which is a quarter million in a year. ${ }^{[3]}$

Approximately $42 \%$ of the Bangladesh men are addicted to tobacco, and the number is almost double among the male of slum dwellers in Dhaka, and its adjacent areas are tobacco smokers. ${ }^{[3]}$

Tobacco consumption has a significant association with several health problems. Among the eight leading causes of morbidity and mortality, tobacco consumption is the major risk factor for six causes. Tobacco is consumed in many different forms, including cigarettes or bidis or pan masala in South and South-East Asia. ${ }^{[4]}$ Tobacco is the only legal consumer product that harms to its consumers as well as the people who are surrounding to the consumers. Although the harmfulness of tobacco is very well known to all, tobacco use is increasing due to low prices, belligerent and widespread marketing, lack of awareness about its dangers, and inconsistent public policies against its use. ${ }^{[5]}$

Smoking among the students, especially in Bangladesh, is gradually increasing. ${ }^{[6]}$ University students constitute high-risk groups regarding the adoption of risky behavior, such as smoking and illicit substances use. ${ }^{[7,2]}$ However, there is a scarcity of information in this regard. The current research aimed to find out the prevalence of tobacco consumption among the students and the factors associated with tobacco consumption in one of the private universities in Bangladesh, at the Daffodil International University (DIU).

\section{METHOD}

This cross-sectional study was conducted at Daffodil International University from January to May 2017. The target population of this study was students of DIU who were available during this study and give their consent for participation. The sampling unit was an individual student, and purposive sampling was used. All the five Faculties of DIU included, and the semesters of this study were also maintained. A male student of DIU who was in their second or higher semesters and was available at the time of this study was included in this study, where DIU students who were sick at the time of this study and students who were studying at any other educational institutions other than DIU were excluded from this study.

\section{Sample Size Determination}

DIU has more than 20000 students. The following formula was used to calculate sample size

$\mathrm{n}=\frac{z^{2} p q}{d^{2}}$

here, $\mathrm{n}$ is the desired sample size

$z=95 \%$ confidence value which is 1.96

$p$ is proportion in target population estimated to have the characteristics. In this study, we assume $p$ is $50 \%$ or 0.50

$q=1-p=1-0.50=0.50$

$d=$ degree of accuracy required, usually set at 0.05 level.

Therefore,

$\mathrm{n}=(1.96) 2(0.5)(1-0.5) / 0.052$

$=(1.96) 2(0.5)(0.5) / 0.052$

$=0.9604 / 0.0025=384.16$

$\mathrm{n}=384$

The research instrument used in this study was a self-administered structured questionnaire. Data were collected using a self-administered questionnaire. A well-constructed questionnaire was distributed to the selected students. The questionnaire included information about tobacco consumption and socio-demographic characters. Data were analyzed using Statistical Package for Social Sciences and Microsoft Excel. Simple frequencies, means and standard deviations were utilized for continuous variables, and bivariate analyses like chi-square were carried out as appropriate. This study was ethically approved by the research ethics committee of the Faculty of Allied Health Sciences of DIU on 09/04/2017. All participants signed a written consent form.

\section{RESULTS}

A total of 384 male students participated in this study. Distributions of the respondents by sociodemographic characteristics are summarized in Table 1.

This study documented the prevalence of smokers in this study. Among the respondents, 186 (48.4\%) found smokers and 198 (51.6\%) were nonsmokers. Among smoker respondents, 178 (95.7\%) were cigarette smokers, only 1 (0.5\%) of Bidi smokers and 7 (3.8\%). Prevalence and patterns of tobacco consumptions among the respondents are summarized in Table 2. 


\section{Table 1. Distributions of the respondents by socio- demographic characteristics}

\section{Variable}

Frequency (n) Percentage (\%)

Age

18-23 years

24-28 years

29-31 years

Number of family members

$$
\begin{aligned}
& 1-3 \\
& 4-5
\end{aligned}
$$$$
\text { 6-25 }
$$

Monthly family income BDT

5000-13000

15000-25000

26000-40000

41000-60000

65000-100000

Faculty of study

Faculty of Science

and Technology

Faculty of Business \&

Economics

Faculty of Humanities \&

Social Sciences

Faculty of Engineering

Faculty of Allied Health

Sciences

\section{Religion}

Muslim

Hindus

Christian

Buddhist

Others

Present residence type

Mess

Home

Lodging/relative house

Hostel

Personal income

Yes

No

Source of personal income

Job holder

Business

Other

Monthly personal income BDT

2000-5000

5000-10000

12000-100000
25.3

0.8

38

255

91

12

81

134

90

67

122

67

13

119

63

344

35

2

2

1

235

107

10

32

87

297

67

12

8

10

41

36

\section{Table 1. CONT.}

Variable

Frequency (n)

Percentage (\%)

Monthly personal expenditure BDT

1000-5000

11.5

5000-10000

41.4

11000-80000

47.1

Father's educational level

No formal education

3.4

Up to class VI

12.0

Up to SSC

16.4

Up to HSC

20.8

Up to Bachelor's degree

24.7

Master's degree or higher

22.7

Mother's educational level

No formal education

4.7

Up to class VI

20.8

Up to SSC

28.1

Up to HSC

25.5

Up to Bachelor's degree

Master's degree or higher

12.5

8.4

Father's occupation

Government service

25.3

Non-government service

9.6

Business

41.1

Farmer

8.1

Retired

Jobless

Others

Mother's occupation

Service holder

14.6

House wife

83.9

Others

56

1.5

Number of people living a room

Single

23.2

2 people

29.1

3 people

28.4

4 people

19.3

Place of residence

Urban

67.2

Rural

258

32.8

Had affair with someone

Yes

165

43.0

No

219

57.0

BDT: Bangladeshi Taka (currency); \#the value is calculated after omitting outlier.

Slightly higher than three-fourths 143 (76.9\%) of the respondents started smoking before university study, and 43 (23.1\%) started smoking after university study. Nearly onethird 117 (30.5\%) of the students had family members who 
Table 2. Prevalence and patterns of tobacco consumptions among the respondents

Variable Frequency (n) Percentage (\%)

Smoke tobacco $(n=384)$

$\begin{array}{lll}\text { Yes } & 186 & 48.4 \\ \text { No } & 198 & 51.6\end{array}$

Type of smoking do you

usually use $(n=186)$

$\begin{array}{lcc}\text { Cigarette } & 178 & 95.7 \\ \text { Bidi } & 1 & 0.5 \\ \text { E-cigarette } & 7 & 3.8\end{array}$

Frequency of smoking $(n=186)$

$119 \quad 63.9$

I smoke sometimes

44

23.7

I smoke occasionally

23

12.4

Number of sticks smoke

in a day $(n=186)$

$\begin{array}{lcc}\leq 10 & 146 & 78.5 \\ 11-20 & 31 & 16.7 \\ >20 & 9 & 4.8 \\ & & \end{array}$

Type of SLT usually used $(n=30)$

Zarda

Gul

Sadapata

Others

$16 \quad 53.3$

$5 \quad 16.7$

$5 \quad 16.7$

$4 \quad 13.3$

Frequency of SLT consumption $(n=29)$

I use SLT daily
I use SLT sometimes
I use SLT occasionally

$15 \quad 51.7$

$6 \quad 20.7$

$8 \quad 27.6$

Amount of SLT consumed

in a day $(n=29)$

$\begin{array}{lcc}\leq 3 & 17 & 58.6 \\ 4-7 & 11 & 37.9 \\ >7 & 1 & 3.5\end{array}$

SLT: Smokeless tobacco.

smoked while 267 (69.5\%) of the students did not. Slightly higher than a quarter of the students had one smoker family member 97 (82.9\%), followed by 20 (17.01\%) who have two to four smokers in their families. Initiation, influencers and family member's tobacco consumption status of the respondents are summarized in Table 3.

In the evidence of respondent's knowledge of tobacco consumption and its effects on health more than four-fifths of the respondent's knowledge related to the following issue were found correct: Tobacco is harmful 328 (90.9\%), smoke from other people's cigarette is harmful $332(91.0 \%)$, and tobacco causes cancer $317(85.0 \%)$ and health warning of cigarette packet 351 (91.6\%). Knowledge of tobacco consumption of the respondents are summarized in Table 4.

This study found that there was a significant association between smoking behaviors and the age group $(p=0.001)$, number of family members $(p=0.026)$, faculty of study $(p=0.001)$ of the respondents. There was asignificant association found between smoking behaviors and the place of residence $(p<0.001)$, present residence type $(p<0.001)$, and personal income $(p=0.002)$ of the respondents. A significant association found between smoking behaviors and the mother's educational level $(p=0.014)$ and father's occupation $(p=0.008)$ of the respondents. Association of sociodemographic characteristics and smoking behavior of the respondents are summarized in Table 5. There was evidence of the association between smoking behavior and knowledge on tobacco consumption and its health effect. A significant association found between smoking behavior and knowledge on tobacco consumption causes mouth infection $(p=0.008)$, stomach infection $(p=0.001)$, loss of taste $(p=0.037)$, loss of appetite $(p<0.001$, dental plaque $(p=0.002)$, ulcer $(p<0.001)$, and heart disease. There was a significant association between smoking behaviors and the health problems that the respondents were suffering during the last six months and types of disease those were consulted with the doctor $(p=0.005)$. There was a significant association between smoking behaviors and the health problems respondents were suffering from, which is stress $(p=0.010)$. Association of knowledge, health status and smoking behavior of the respondents are summarized in Table 6.

\section{DISCUSSION}

This study revealed the prevalence of tobacco consumption among male students at DIU. The overall prevalence of current smoking among the respondents in our study was $48.4 \%$. This prevalence is remarkably lower than the reports from other surveys conducted in Bangladesh in which the prevalence of current smoking was $60.2 \%$, where males smoked at higher rates than females. ${ }^{[8]}$

Our findings show that the overall prevalence of smokeless tobacco (SLT) uses among students is $7.8 \%$, which is lower than the reported estimates from the Global Adult Tobacco Survey 2009 study. ${ }^{[9]}$ Data found that the proportions of smokers were also significantly high among the rural students compared to similar urban finding was also stated by other research in Bangladesh. ${ }^{[10]}$ It is found 


\section{Table 3. Initiation, influencers and family member's tobacco consumption status of the respondents}

\section{Variable}

Age initiated smoking (years) $(n=186)$

5-17

$18-22$

23-27

Initiation of smoking and university study $(n=186)$

Before university

After university

Family Member/s smoke $(n=384)$

Yes

No

Number of family members who smoke $(n=117)$

One member

Two to four members

Age initiated SLT consumption (years) $(n=29)$

5-17

$18-22$

23-24

Initiation of SLT consumption and university study $(n=29)$

Before university

After university

Influencers of smoking

Friends

Yes

No

Siblings

Yes

No

Relatives

Yes

No

Movie

Yes

No

Others

Yes

No

Influencers of SLT consumption

Friends

Yes

No

Parents

Yes

No

Teachers

Yes

No

Movie

Yes

No

Others

Yes

No

Family members who use tobacco

Fathers

Mothers

Siblings

Other family members
Frequency

Percentage (\%)

54

123

9

143

43

117

267

97

20

13

14

2

25

4

154

32

4

182

7

179

10

176

16

170

22

7

2

27

1

28

2

27

2

27

Smoking (\%)

63.5

0.8

24.6

11.1
29.1

66.1

4.8

76.9

23.1

30.5

69.5

82.9

17.1

44.8

48.2

7.0

86.2

13.8

82.8

17.2

2.2

97.8

3.8

96.2

5.4

94.6

8.6

91.4

75.9

24.1

6.9

93.1

3.4

96.6

6.9

93.1

6.9

93.1

SLT (\%)

48.0

28.0

10.7

13.3

SLT: Smokeless tobacco. 
Table 4. Knowledge of tobacco consumption of the respondents

\section{Variable}

Frequency (n) Percentage (\%)

Tobacco is harmful $(n=361)$

Correct

328

Incorrect

33

90.9

Smoke from other people's

cigarette is harmful $(n=365)$

Correct

332

Incorrect

33

91.0

9.0

Tobacco consumption

cause cancer $(n=373)$

Correct

317

Incorrect

56

85.0

15.0

Tobacco consumption cause

mouth infection $(n=373)$

Correct

Incorrect

240

35.7

64.3

Tobacco consumption cause

stomach infection $(n=373)$

Correct

Incorrect

279

25.2

74.8

Tobacco consumption cause

loss of taste $(n=373)$

Correct

Tobacco consumption cause

loss of appetite $(n=361)$

Correct

Incorrect

Tobacco consumption cause

dental stone/plaque $(n=373)$

Correct

Incorrect

Tobacco consumption cause

stroke $(n=373)$

Correct

Incorrect

Tobacco consumption cause

ulcer $(n=373)$

Correct

Incorrect

Tobacco consumption cause heart disease $(n=373)$

Correct

Incorrect

\section{Table 4. CONT.}

Variable

Frequency (n) Percentage (\%)

Noticed about health warning

on the cigarette packet $(n=383)$

Correct

351

91.6

Incorrect

32

8.4

Type of health warning

observed $(n=364)$

Text warning

105

28.9

Pictorial warning

35

9.6

Both

Type of health warning which is

more understandable $(n=362)$

Text warning

67

18.5

Pictorial warning

71

19.6

Both

224

61.9

that there is a significant association between smoking behaviors and some socio-demographic characteristics of the respondents like the age group, number of family members, faculty, and place of residence, present residence type, personal income, father's educational level, mother's educational level, father's occupation and the affair to love of the respondents which agrees with the other studies of Asia. ${ }^{[10,5]}$

The initiation of tobacco smoking was found to be dramatically increased after 18 years of age until 22 years, which agrees with the other study conducted in Dhaka, Bangladesh. ${ }^{[8]}$ The majority of the students who participated in this study were knowledgeable about the link between smoking cigarettes and chronic diseases, which is encouraging for future programs targeting smoking cessation. The findings of the present study are consistent with Dhaka's ${ }^{[8]}$ study. Friends were considered to have the highest influence on initiating tobacco consumption. Other researchers had similar results. ${ }^{[11]}$ This study reveals most of the student smokers started smoking before university study, which contradicts that of the national survey of the United States college students, which considers college time to be a time when many students are trying a range of tobacco products. ${ }^{[12]}$ This study showed that smoking was associated with the respondents aged 18-23 years. Another study of Nepal had similar results. ${ }^{[2]}$ The mean age of initiating tobacco smoking was 18.66 years, whereas that of initiating SLT was 17.72 years. This finding remarkably higher than that of study in Nepal in which the mean age of initiating tobacco smoking was 13.79 years, whereas that of initiating tobacco chewing was 13.58 years. ${ }^{[2]}$ This study revealed 


\section{Table 5. Association of the socio-demographic characteristics and smoking behavior of the respondents}

\section{Variable}

Smoking behavior

Yes $(n=186)$

Age, $\mathrm{n}(\%)$

18-23 years

24-28 years

29-31 years

Number of family members, $\mathrm{n}(\%)$

$1-3$

4-5

6-25

Faculty of study, n (\%)

Faculty of Science and Technology (FSIT)

Faculty of Business \& Economics (FBE)

Faculty of Humanities \& Social Sciences (FHSS)

Faculty of Engineering (FE)

Faculty of Allied Health Sciences (FAHS)

Place of residence, $\mathrm{n}(\%)$

Rural

Urban

Present residence type, $\mathrm{n}(\%)$

Mess

Home

Lodging/relative house

Hostel

Personal income, $\mathrm{n}$ (\%)

Yes

No

Mother's educational level, $\mathrm{n}(\%)$

No formal education

Up to class VI

Up to SSC

Up to HSC

Up to Bachelor's degree

Master's degree or higher

Father's occupation, n (\%)

Government service

Non-government service

Business

Farmer

Retired

Jobless

Others

Affair with someone, $\mathrm{n}$ (\%)

Yes

No
123 (66.1)

60 (32.3)

3 (1.6)

$15(8.1)$

136 (73.1)

35 (18.8)

59 (31.7)

38 (20.4)

7 (3.8)

66 (35.5)

$16(8.6)$

$146(78.5)$

40 (21.5)

103 (55.4)

48 (25.8)

4 (2.1)

31 (16.7)

55 (29.6)

131 (70.4)

4 (2.2)

29 (15.6)

53 (28.5)

55 (29.6)

30 (16.0)

$15(8.1)$

54 (29.0)

$15(8.1)$

84 (45.2)

7 (3.8)

14 (7.5)

3 (1.6)

9 (4.8)

89 (47.8)

97 (52.2)
No $(n=198)$

Chi-square

p

7.3

0.026

$119(60.1)$

56 (28.3)

63 (31.8)

17.8

0.001

29 (14.7)

$6(3.0)$

53 (26.8)

47 (23.7)

112 (56.6)

21

$<0.001$

86 (43.4)

132 (66.7)

33

$<0.001$

59 (29.8)

6 (3.0)

$1(0.5)$

32 (16.2)

10

0.002

$166(83.8)$

$14(7.1)$

17.5

0.014

51 (25.7)

55 (27.8)

43 (21.7)

$18(9.1)$

17 (8.6)

43 (21.7)

17.3

0.008

22 (11.1)

74 (37.4)

24 (12.1)

11 (5.6)

3 (1.5)

21 (10.6)

76 (38.4)

3.507

0.061 
Table 6. Association of health status, knowledge and smoking behavior of the respondents

\begin{tabular}{|c|c|c|c|c|}
\hline \multirow[t]{2}{*}{ Variable } & \multicolumn{2}{|c|}{ Smoking behavior } & \multirow[t]{2}{*}{ Chi-square } & \multirow[t]{2}{*}{$\mathbf{p}$} \\
\hline & Yes & No & & \\
\hline \multicolumn{5}{|c|}{ Tobacco consumption cause mouth infection $(n=373)$} \\
\hline No & $130(71.0)$ & $110(57.9)$ & & \\
\hline \multicolumn{5}{|c|}{ Tobacco consumption cause stomach infection $(n=373)$} \\
\hline \multicolumn{5}{|c|}{ Tobacco consumption cause loss of taste $(n=373)$} \\
\hline Yes & $42(23.0)$ & $62(32.6)$ & 4.34 & 0.037 \\
\hline No & $141(77.0)$ & $128(67.4)$ & & \\
\hline \multicolumn{5}{|c|}{ Tobacco consumption cause loss of appetite $(n=373)$} \\
\hline Yes & $24(13.1)$ & $53(27.9)$ & 12.430 & $<0.001$ \\
\hline \multicolumn{5}{|c|}{ Tobacco consumption cause ulcer $(n=373)$} \\
\hline Yes & $29(15.8)$ & $63(33.2)$ & 15.033 & $<0.001$ \\
\hline No & $154(84.2)$ & $127(66.8)$ & & \\
\hline \multicolumn{5}{|c|}{ Tobacco consumption cause heart disease $(n=373)$} \\
\hline Yes & $47(25.7)$ & $80(42.1)$ & 11.195 & 0.001 \\
\hline No & $136(74.3)$ & $110(57.9)$ & & \\
\hline \multicolumn{5}{|c|}{ Faced any type of disease during last six months $(n=383)$} \\
\hline Yes & $30(16.1)$ & $65(33.0)$ & 14.591 & $<0.001$ \\
\hline No & $156(83.9)$ & $132(77.0)$ & & \\
\hline \multicolumn{5}{|c|}{ Type of disease consulted/treated $(n=66)$} \\
\hline Ophthalmic disease & $0(0.0)$ & $4(9.8)$ & & \\
\hline Oral/Dental disease & $2(8.0)$ & $0(0.0)$ & & \\
\hline Cough & $2(8.0)$ & $3(7.3)$ & & \\
\hline Other & $3(12.0)$ & $17(41.5)$ & & \\
\hline \multicolumn{5}{|l|}{ Had stress $(n=384)$} \\
\hline Yes & $80(43.0)$ & $69(34.8)$ & 2.7 & 0.010 \\
\hline No & $106(57.0)$ & $129(65.2)$ & & \\
\hline
\end{tabular}

that respondent's knowledge of tobacco consumption causes cancer. This study is consistent with another study conducted in Iraq in which the knowledge score was high for lung cancer. ${ }^{[13]}$ The majority of the respondents agreed that Tobacco was harmful, another study in South Africa had similar findings where most of the adult respondents agreed that the health effects of smoking were serious or very serious. ${ }^{[14]}$

\section{CONCLUSION}

The prevalence of tobacco consumption among the students of private universities is very high (48.4\%), regardless of the health risks associated with tobacco use. This study reveals that tobacco smoking is initiated before university admission and continues throughout the university years. Most of the student's tobacco consumption is influenced by friends. Significant association with tobacco uses and respondent's socio-demographic characteristics, such as 
age, place of residence, knowledge of the consequences of tobacco consumption, health problems that the respondents were suffering and the affair of love, frequency of library use by the respondents. The campaigns which would work against tobacco consumption should target the youth population, especially university students. This study has been conducted at the selected private university in Bangladesh; further studies in this regard can be helpful. University can establish anti-tobacco regulating cell to monitor and counseling the students.

\section{Disclosures}

Peer-review: Externally peer-reviewed.

Conflict of Interest: None declared.

Ethics Committee Approval: Research Ethics Committee of the Faculty of Allied Health Sciences, Daffodil International University, Dhaka, Bangladesh on 09/4/2017.

Authorship Contributions: Concept - S.M.F.; Design - S.M.F., A.B.M.A.C.; Supervision - A.B.A.M.C., K.H., R.K.; Materials - L.N., D.M-S.; Data collection \&/or processing - S.M.F.; Analysis and/or interpretation - S.M.F.; Literature search - S.M.F., K.H.; Writing S.M.F., R.D.L.R-E.; Critical review - K.H., R.K., L.N.

\section{REFERENCES}

1. World Health Organization, 2015. WHO report on the global tobacco epidemic 2015: raising taxes on tobacco. World Health Organization. https://www.who.int/tobacco/global_ report/2015/report/en/ [Accessed date 6.10.2017]

2. Singh Pradhan PM, Kalra S. Factors Associated with Tobacco Use among Female Adolescent Students in Dharan Municipality of Eastern Nepal. J Nepal Health Res Counc 2015;13(31):220-5.

3. The Daily star. Manas seminar told citing WHO report, Smoking kills 2.5 lakh a year in Bangladesh. March 8, 2015.

4. Islam SM, Mainuddin AK, Bhuiyan FA, Chowdhury KN. Prevalence of tobacco use and its contributing factors among adolescents in Bangladesh: Results from a population-based study. South Asian J Cancer 2016;5(4):186-8. [CrossRef]

5. Fasoro AA, Rampal G, Rampal L, Mohd Sidik S, Said S. Prevalence of smoking and its associated factors among university staff. Malaysian J Med Health Sci 2013;9(2);45-51.

6. Khan NR, Mahmood AR. Pattern of tobacco consumption and related factors among the people residing in a rural area. Bangladesh Med J 2015;44(1):32-5. [CrossRef]

7. Rahman M, Arif MT, Razak MF, Suhaili R, Zainab T, Cliffton A, et al. Factor associated with tobacco use among the adult population in Sarawak, Malaysia: a cross sectional study. Epidemiology Biostatistics and Public Health 2015;12(1):1-9.

8. Hossain S, Hossain S, Ahmed F, Islam R, Sikder T, Rahman A. Prevalence of tobacco smoking and factors associated with the initiation of smoking among university students in Dhaka, Bangladesh. Cent Asian J Glob Health 2017;6(1):244. [CrossRef]

9. World Health Organization. 2009. Global health risks: mortality and burden of disease attributable to selected major risks. World Health Organization. https://www.who.int/healthinfo/ global_burden_disease/GlobalHealthRisks_report_full.pdf [Accessed date 18/09/2017]

10. Tarafdar MMA, Nahar S, Rahman MM, Hussain SMA, and Zaki $M$. Prevalence and determinants of smoking among the college students in selected district of Bangladesh. Bangladesh Med J 2009;38(1):3-8. [CrossRef]

11. Alexander C, Piazza M, Mekos D, Valente T. Peers, schools, and adolescent cigarette smoking. J Adolesc Health 2001;29(1):2230. [CrossRef]

12. Rigotti NA, Lee JE, Wechsler H. US college students' use of tobacco products: results of a national survey. JAMA 2000;284(6):699-705. [CrossRef]

13. Dawood OT, Rashan MA, Hassali MA, Saleem F. Knowledge and perception about health risks of cigarette smoking among Iraqi smokers. J Pharm Bioallied Sci 2016;8(2):146-51. [CrossRef] 14. Reddy P, Meyer-Weitz A, and Yach D. Smoking status, knowledge of health effects and attitudes towards tobacco control in South Africa. S Afr Med J 1996;86(11):1389-93. 